\title{
Detection of CDT toxin genes in Campylobacter spp. strains isolated from broiler carcasses and vegetables in São Paulo, Brazil
}

\author{
Aline Feola de Carvalho ${ }^{1}$, Daniela Martins da Silva ${ }^{1}$, Sergio Santos Azevedo ${ }^{2}$, \\ Rosa Maria Piatti ${ }^{1}$, Margareth Elide Genovez ${ }^{1}$, Eliana Scarcelli ${ }^{1}$ \\ ${ }^{1}$ Instituto Biológico, Centro de Pesquisa e Desenvolvimento de Sanidade Animal, São Paulo, SP, Brazil. \\ ${ }^{2}$ Universidade Federal de Campina Grande, Campina Grande, PB, Brazil.
}

Submitted: June 08, 2011; Approved: April 01, 2013.

\begin{abstract}
Campylobacteriosis is a worldwide distributed zoonosis. One of the main virulence factors related to Campylobacter spp. in animals and humans is the cytolethal distending toxin (CDT), encoded by three adjacent genes ( $c d t A, c d t B, c d t C$ ). The occurrence of Campylobacter spp. in samples of vegetables has not been reported in Brazil yet, and has seldom been described in the international literature. The detection of CDT in these strains has not been reported, either. The objectives of the present study were to determine the occurrence of Campylobacter spp. strains carrying virulence factors in samples of poultry and vegetables (lettuce and spinach) from different points of sale, thus verifying if vegetables are as an important vehicle for potentially virulent Campylobacter spp. strains as poultry. Twenty four strains were identified as Campylobacter jejuni by phenotypic and genotypic methods: 22 from broiler carcasses and two from lettuce samples. Three strains were identified as Campylobacter coli: two from broiler carcasses and one from lettuce. The presence of the $c d t$ genes were detected in 20/24 (83.3\%) C. jejuni strains, and 3/3 (100\%) C. coli strains. The isolation of Campylobacter spp. strains with the $c d t$ gene cluster in lettuce samples points to a new possible source of contamination, which could have an impact in the vegetable production chain and risk to public health. Results show that potentially virulent $C$. jejuni and $C$. coli strains remain viable in samples of broiler carcasses and vegetables at the points of sale.
\end{abstract}

Key words: Campylobacter spp., cytolethal distending toxin (CDT), broiler carcasses, vegetables, Multiplex-PCR.

\section{Introduction}

Campylobacteriosis is a worldwide distributed zoonosis. Campylobacter jejuni and Campylobacter coli are ubiquitous microorganisms, which are found in the environment, as well as in the gastrointestinal tract of animals, where they live as pathogenic or commensal agents (Altekruse, 1998; Scarcelli et al., 2005). These species are the most common causes of diarrhea in children in developing countries, and of gastro-enteritis in industrialized countries (Carvalho et al., 2001).

Foodborne transmission is the main route in human contamination by Campylobacter spp. The most significant risk factors include the contamination of poultry carcasses in slaughterhouses and consequent consumption and/or handling of raw or undercooked meat. The ingestion of unpasteurized milk or untreated water, cross-contamination during food preparation or direct contact with infected animals are other risk factors (Rozynek et al., 2005; Hussain et al., 2007).

Environmental routes of transmission of Campylobacter spp. should also be emphasized, including plants, insects, and non-chlorinated water contaminated by animal feces, which few studies have considered as a vehicle for the dissemination of the microorganism, particularly to foods of non-animal origin (Kumar et al., 2001). Fresh vegetables, especially when raw, may also be a source of transmission for several human pathogens (Abadias et al.,

Send correspondence to: A.F. Carvalho. Instituto Biológico, Centro de Pesquisa e Desenvolvimento de Sanidade Animal. Av. Conselheiro Rodrigues Alves, 1252. CEP 04014-002, São Paulo, SP, Brazil. E-mail: linebio@gmail.com. 
2008). In this case, contamination by Campylobacter spp. may occur before or after their purchase (Evans et al., 2003).

The cytolethal distending toxin (CDT) is one of the main virulence factors related to Campylobacter spp. pathogenesis in humans and animals. It causes diarrhea by interfering with the division and differentiation of cells in intestinal crypts (Wassenaar, 1997; Park, 2002). The toxin activity is encoded by the $c d t$ gene cluster, made up of three adjacent genes: $c d t A, c d t B$ and $c d t C$ (Martinez et al., 2006). All the three subunits are required for full toxin activity; $c d t B$ encodes the active/toxic component of the toxin, while $c d t A$ and $c d t C$ are involved with binding to and internalization into the host cell (Abuoun et al., 2005; Jeon et al., 2005).

The protein produced by gene $c d t B(\mathrm{CdtB})$ potentiates a cascade leading to cell cycle block, whereas the proteins of genes $c d t A$ and $c d t C$ function as dimeric subunits, with bind $c d t B$ and delivers in to the cell interior. Once in the cell, CdtB enters the nucleus and exhibits a DNase-I like that results in DNA double-strand breaks. CDT blocks the G2/M phase of eukaryotic cells prior to cell division, induces a cytoplasmic distention and ultimately causes cell death (Jeon et al., 2005; Smith and Bayles, 2006).

The result of CDT activity can differ depending on the type of eukaryotic cell affected. CDT contributes to campylobacteriosis pathogenesis by inhibiting both cellular and humoral immunity via apoptosis of immune cells, and generating the necrosis of epithelial cells and fibroblasts involved in the repair of lesions produced by pathogens, which results in slow healing and production of disease symptoms (Smith and Bayles, 2006).

The occurrence of Campylobacter spp. in vegetables has rarely been described in the literature, and CDT detection in these strains has never been reported (Park and Sanders, 1992; Kumar et al., 2001; Chai et al., 2007). However, it is essential to assess if vegetables are as an important vehicle for Campylobacter spp. as poultry meat, which is known as the main source of foodborne transmission of campylobacteriosis. Lettuce and spinach are described in the international literature as the main vegetable sources of human infection by Campylobacter spp. (Park and Sanders, 1992; Kumar et al., 2001; Brandl et al., 2004; Hussain et al., 2007). Nevertheless, this is the first study in Brazil on CDT found in vegetables.

The objectives of the present study were to determine the occurrence of Campylobacter spp. strains carrying $c d t$ genes in samples of poultry and vegetables (lettuce and spinach), and to verify if vegetables are as an important vehicle for potentially virulent Campylobacter spp. strains as poultry at different points of sale.

\section{Materials and Methods}

A total of 194 broiler carcasses refrigerated were analyzed. The samples were purchased in two supermarkets $(\mathrm{n}=40)$, two street markets $(\mathrm{n}=40)$, and two slaughterhouses $(\mathrm{n}=114)$ in São Paulo. As for vegetables, 80 samples were purchased in two supermarkets $(\mathrm{n}=20$ samples of spinach, and $n=20$ of lettuce) and two street markets ( $n=20$ samples of spinach, and $n=20$ of lettuce) in the same state. Poultry carcasses and vegetables were collected from two supermarkets and two street markets, 20 specimens by collection, in a total of eight samplings, between April and October, 2008. Two samplings were performed in two slaughterhouses, with the collection of 60 carcasses in the first samplings and 54 in the second, carried out between March and June, 2009.

Samples were submitted for bacteriological examination. The isolation and biochemical identification of $C$. jejuni and C. coli was performed according to the Bacteriological Analytical Manual (Hunt et al., 2001; Carvalho et al., 2010).

In order to confirm the biochemical identification, the isolated strains were submitted to two-step PCR reactions with primers described by Linton et al. (1997). The first was targeted to the hip gene, which encodes the enzyme hippuricase, responsible for the amplification of a 735-base pair (bp) fragment only found in C. jejuni; and the second was targeted to the gene encoding the enzyme aspartokinase, which amplifies a 500-bp fragment found in C. coli.

Isolated Campylobacter strains had their DNA extracted with the commercial kit Ilustra Bacterial Genomic PREP Mini Spin (GE Healthcare), used according to the manufacturer's instructions.

Analysis of the amplified products was carried out by electrophoresis in $2.0 \%$ agarose gel stained with ethidium bromide $(0.5 \mu \mathrm{g} / \mathrm{mL})$. Gels were photographed under ultraviolet light (300-320 nm) with a Kodak DC/120 Zoom digital camera. Images were analyzed using the 1D Image Analysis software (Kodak Digital Science). Campylobacter jejuni ATCC 33291 and Campylobacter coli CDC A3315 were used as positives controls.

Multiplex-PCR with primers described by Asakura et al. (2008) was used to detect the simultaneous presence of $c d t A, c d t B$ and $c d t C$ in the $C$. jejuni and $C$. coli strains that were isolated in the study. In $C$. jejuni, the $c d t A$ gene corresponds to a fragment of $631 \mathrm{bp}$; $c d t B$, to a fragment of $714 \mathrm{bp}$; and $c d t C$, to a fragment of $524 \mathrm{bp}$.

In $C$. coli, the $c d t A$ gene corresponds to a fragment of $329 \mathrm{bp} ; c d t B$, to a fragment of $413 \mathrm{bp}$; and $c d t C$, to a fragment of $313 \mathrm{bp}$. Due to the similarity between the number of base pairs in the fragments amplified corresponding to genes $c d t A(329 \mathrm{pb})$ and $c d t C(313 \mathrm{pb})$, two Multiplex-PCR reactions were carried out: one with $c d t A$ and $c d t B$ primers, and the other with $c d t B$ and $c d t C$ primers.

Detection of $c d t$ genes in $C$. jejuni: PCR buffer $10 \mathrm{X}$ (500 mM KCl, $15 \mathrm{mM} \mathrm{MgCl}, 100 \mathrm{mM}$ TRIS-HCl, $\mathrm{pH}$ 9.0); $1.5 \mathrm{mM} \mathrm{MgCl}_{2} ; 200 \mathrm{mM}$ dNTPs (200 mM of each nucleotide dCTP, dATP, dGTP, dTTP); 20 pmol of each primer (CjspAU2, CjspAR2, CjSPBU5, CjSPBR6, 
CjspCU1 and CjspCR2); 1.0 U Taq DNA polymerase (Invitrogen), and $10 \mu \mathrm{L}$ of extracted DNA were mixed to a final volume of $50 \mu \mathrm{L}$. Thermocycler PT 200 (MJ Research) was used in an amplification cycle preceded by initial denaturation at $94{ }^{\circ} \mathrm{C}$ for $5 \mathrm{~min}$, and followed by 30 cycles of denaturation at $94^{\circ} \mathrm{C}$ for $30 \mathrm{~s}$, hybridization at $55^{\circ} \mathrm{C}$ for $30 \mathrm{~s}$, extension at $72{ }^{\circ} \mathrm{C}$ for $30 \mathrm{~s}$, and final extension at $72{ }^{\circ} \mathrm{C}$ for $10 \mathrm{~min}$, in a procedure adapted from Asakura et al. (2008).

Detection of $c d t$ genes in C. coli: Multiplex-PCR was carried out as previously described, with different primers (CcspAU1, CcspAR1, CcSPBU5, CcSPBR5) and (CcSPBU5, CcSPBR5, CcspCU1, CcspCR1), in a procedure adapted from Asakura et al. (2008). The analysis of the amplified products was carried out according to the procedures used for the hippuricase and aspartokinase genes.

Statistical analysis was based on the chi-square test $\left(X^{2}\right)$ and Fisher's exact test, with significance level set at $\mathrm{p}<0.05$, according to Callegari-Jacques (2003). Statistical analyses were carried out in EpiInfo 6.04 (Dean, 1994).

\section{Results}

Campylobacter spp. strains were isolated in 21/194 $(10.8 \%)$ broiler carcasses and in 3/40 (7.5\%) samples of lettuce. As for spinach, none of the samples were positive for Campylobacter spp. Twenty four strains were identified as C. jejuni: 22 from broiler carcasses, and two from lettuce samples. Three strains were identified as $C$. coli: two from broiler carcasses, and one from lettuce samples. C. jejuni and $C$. coli strains isolated in samples of animal and vegetable origin were found in supermarkets, street markets and slaughterhouses (Table 1).

All C. jejuni and C. coli strains were identified by phenotypic methods and confirmed by genotyping using PCR for detection of the genes encoding the enzymes hippuricase and aspartokinase.

The $c d t$ gene cluster was detected in 20/24 (83.3\%) C. jejuni strains: 18 from broiler carcasses (seven purchased in slaughterhouses, seven in supermarkets, and four in street markets), and two from lettuce samples purchased in street markets. The $c d t$ gene complex was not found in $4 / 24$ $(16.7 \%)$ C. jejuni strains (Table 1; Figure 1) isolated in broiler carcasses from slaughterhouses (strains 18, 20, 22 and 24).

Genes $c d t A, c d t B$ and $c d t C$ were simultaneously detected in 16/20 (80\%) C. jejuni strains positive in Multiplex-PCR. In $2 / 20(10 \%)$ strains, only gene $c d t B$ was found in broiler carcasses from street markets (strains 1 and 2). In $2 / 20(10 \%)$ strains, only gene $c d t C$ was found in broiler carcasses from slaughterhouses (strains 17 and 19) (Table 1; Figure 1).

The presence of the $c d t$ gene cluster was detected in $3 / 3(100 \%)$ C. coli strains, two from broiler carcasses and one from a lettuce sample, both purchased in street markets.
Table 1 - Classification of Campylobacter spp. strains according to food source, point of sale, and detection of the $c d t$ gene complex.

\begin{tabular}{|c|c|c|c|c|c|c|}
\hline Strain & Species & Food source & Point of sale & $c d t A$ & $c d t B$ & $c d t C$ \\
\hline 1 & C. jejuni & $\mathrm{BC}$ & SM & - & + & - \\
\hline 2 & C. jejuni & $\mathrm{BC}$ & SM & - & + & - \\
\hline 3 & C. jejuni & $\mathrm{BC}$ & SM & + & + & + \\
\hline 4 & C. jejuni & $\mathrm{BC}$ & SP & + & + & + \\
\hline 5 & C. jejuni & $\mathrm{BC}$ & SP & + & + & + \\
\hline 6 & C. jejuni & $\mathrm{BC}$ & SP & + & + & + \\
\hline 7 & C. jejuni & $\mathrm{BC}$ & SP & + & + & + \\
\hline 8 & C. jejuni & L & SM & + & + & + \\
\hline 9 & C. jejuni & $\mathrm{BC}$ & SM & + & + & + \\
\hline 10 & C. jejuni & $\mathrm{BC}$ & SP & + & + & + \\
\hline 11 & C. jejuni & $\mathrm{BC}$ & SP & + & + & + \\
\hline 12 & C. jejuni & $\mathrm{BC}$ & SP & + & + & + \\
\hline 13 & C. jejuni & $\mathrm{L}$ & SM & + & + & + \\
\hline 14 & C. jejuni & $\mathrm{BC}$ & SL & + & + & + \\
\hline 15 & C. jejuni & $\mathrm{BC}$ & SL & + & + & + \\
\hline 16 & C. jejuni & $\mathrm{BC}$ & SL & + & + & + \\
\hline 17 & C. jejuni & $\mathrm{BC}$ & SL & - & - & + \\
\hline 18 & C. jejuni & $\mathrm{BC}$ & SL & - & - & - \\
\hline 19 & C. jejuni & $\mathrm{BC}$ & SL & - & - & + \\
\hline 20 & C. jejuni & $\mathrm{BC}$ & SL & - & - & - \\
\hline 21 & C. jejuni & $\mathrm{BC}$ & SL & + & + & + \\
\hline 22 & C. jejuni & $\mathrm{BC}$ & SL & - & - & - \\
\hline 23 & C. jejuni & $\mathrm{BC}$ & SL & + & + & + \\
\hline 24 & C. jejuni & $\mathrm{BC}$ & SL & - & - & - \\
\hline 25 & C. coli & $\mathrm{BC}$ & SM & + & + & + \\
\hline 26 & C. coli & $\mathrm{BC}$ & SM & + & + & + \\
\hline 27 & C. coli & L & SM & + & + & + \\
\hline
\end{tabular}

BC: broiler carcasses; L: lettuce; SM: street market; SP: supermarket; SL: slaughterhouse.

All C. coli strains showed cdtA, $\operatorname{cdtB}$ and $c d t C$, simultaneously (Table 1, Figure 2).

No statistically significant differences were observed in relation to the number of Campylobacter spp. positive samples isolated from broiler carcasses and vegetables $(\mathrm{p}=0.060)$; or in animal $(\mathrm{p}=0.820)$ and vegetable samples $(\mathrm{p}=0.241)$ purchased in supermarkets, street markets and slaughterhouses. No statistically significant differences were observed in relation to the presence of $c d t$ genes in broiler carcasses and vegetables $(\mathrm{p}=1.000)$.

\section{Discussion}

C. jejuni and C. coli strains were isolated from 21/194 $(10.8 \%)$ broiler carcasses, a lower frequency to that reported in the literature. In the Unites States, Eyigor et al. (1999) isolated 70/105 (67\%) C. jejuni and 35/105 (33\%) C. coli in poultry carcasses. Rozynek et al. (2005) found 


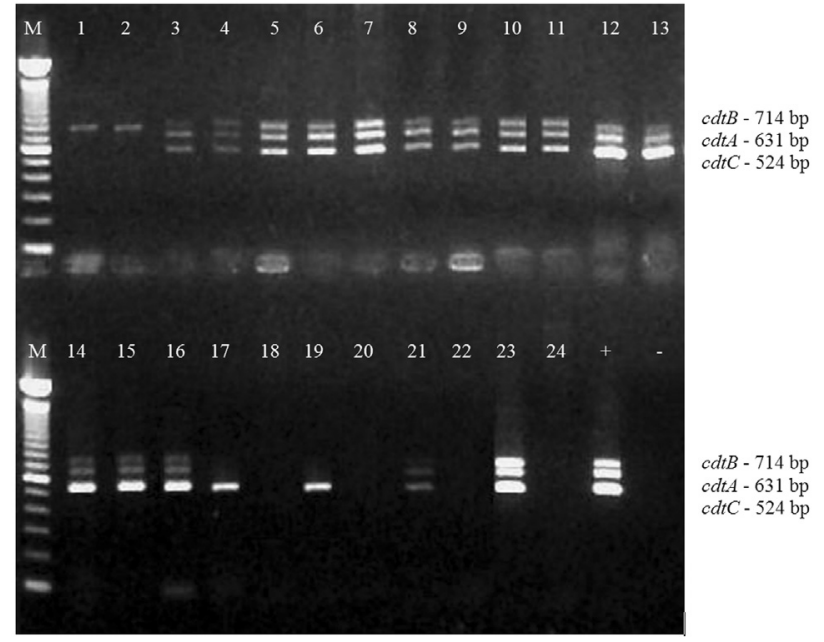

Figure 1 - Multiplex-PCR for $c d t$ genes ( $c d t A, c d t B$ and $c d t C$ ) in $C$. jejuni strains. M: molecular weight marker (100 bp DNA Ladder - Invitrogen); 1 to 24: C. jejuni strains; + Positive control (C. jejuni ATCC 33291); - Negative control.

53/92 (57.6\%) strains of C. jejuni, and 39/92 (42.4\%) of $C$. coli in poultry carcasses in Poland. Mena et al. (2008) identified 99/165 (60.3\%) strains of Campylobacter spp. in poultry samples in Portugal. Prencipe et al. (2007) isolated Campylobacter spp. in 178/392 (45.4\%) poultry carcasses from supermarkets and butcheries in Italy. Kang et al. (2006) isolated Campylobacter spp. in 570/923 (61.8\%) poultry samples from traditional markets, retailers and warehouses in Korea.

The contamination of poultry carcasses often occurs during slaughter, more commonly during scalding and evisceration, when the surface of the carcass is in contact with intestinal microorganisms. Studies in Brazil and other countries have shown a prevalence of $60 \%$ to $100 \%$ posi- tive results for C. jejuni and C. coli in poultry carcasses and organs analyzed immediately after evisceration. However, such frequency decreased to $15 \%$ to $20 \%$ in samples refrigerated or frozen for different periods of time (Sakuma et al., 1992; Castro et al., 1997; Cortez et al., 2006; Prencipe et al., 2007).

Higher levels of chlorine in processing water, coupled with improved hygienic conditions in slaughterhouses may significantly reduce carcass contamination (Mead et al., 1995). However, some Campylobacter spp. strains may survive cleaning and disinfection procedures in poultry slaughterhouses, and may contaminate the carcasses during processing (Peyrat et al., 2008). This may be due to the resistance of Campylobacter spp. strains to disinfectants, mainly chlorine, or to the inefficiency of the cleaning and disinfection procedures used in slaughterhouses.

C. jejuni and C. coli strains were isolated from $3 / 40$ (7.5\%) lettuce samples, and this is the first report about Campylobacter spp. recovered from these samples purchased in São Paulo, Brazil. This frequency was greater than that described by Park and Sanders (1992), who observed 3.1\% lettuce samples positive for Campylobacter spp. The same authors identified C. jejuni strains in $3.3 \%$ of spinach samples, whereas no strain was isolated from this vegetable in the present study. Abadias et al. (2008) did not isolate Campylobacter spp. in lettuce and spinach samples from supermarkets in Spain.

Brandl et al. (2004) isolated C. jejuni from spinach and radish samples. According to these authors, this bacterium is found in the roots, remaining viable in the soil and rhizosphere, and thus leading to sporadic cases of campylobacteriosis associated with the ingestion of these foods. In Pakistan, Hussain et al. (2007) studied the prevalence of Campylobacter spp. in foodstuffs available in retailers, and

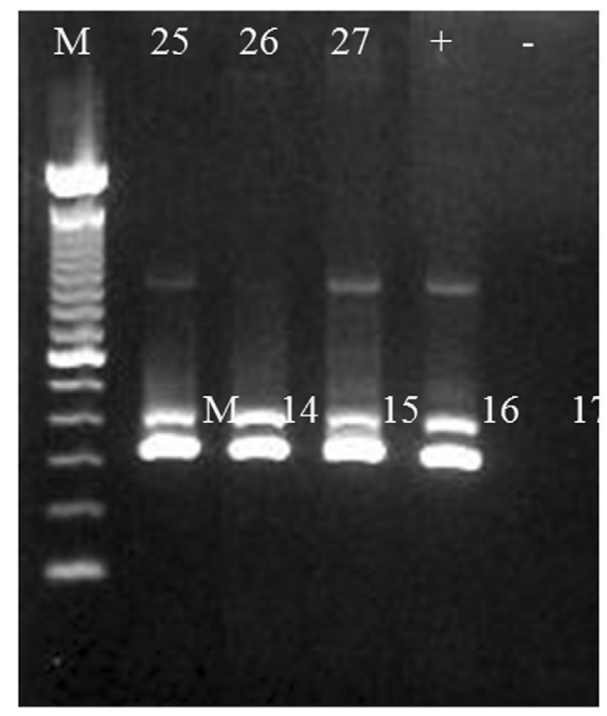

$c d t B-413 \mathrm{bp}$

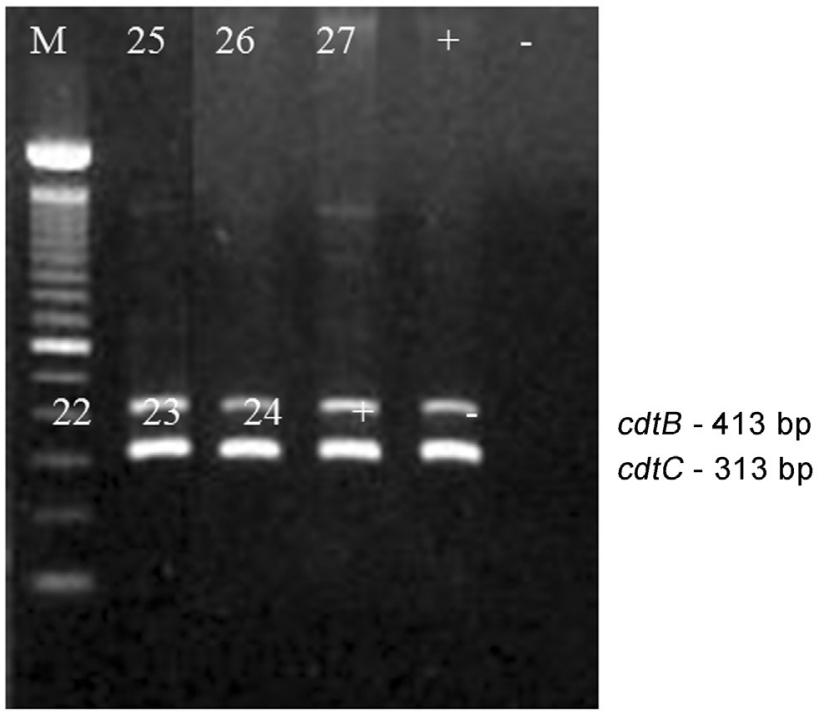

Figure 2 - Multiplex-PCR for $c d t$ genes ( $c d t A, c d t B$ and $c d t C$ ) in $C$. coli. strains M: molecular weight marker (100 bp DNA Ladder - Invitrogen); 25 to 27 : C. coli strains; (+): Positive control (C. coli CDC A3315); (-): Negative control. 
nine $(40.9 \%)$ of the vegetable and fruit salad samples were positive for Campylobacter spp. Kumar et al. (2001) analyzed different vegetable samples collected in markets in India, and isolated 2/56 (3.57\%) C. jejuni, one in spinach and the other in fenugreek.

The presence of $C$. jejuni and $C$. coli in vegetables collected in Brazil may indicate fecal contamination. Campylobacter spp. inhabits the intestinal tract of animals, mainly birds, and their excreta may contaminate the environment (Kumar et al., 2001). Natural fertilizers or water used for irrigation may also be contamination sources (Butzler and Oosterman, 1991). Cross-contamination of vegetables with kitchen utensils used for cutting other foods, such as poultry, may occur during handling and packaging (De-Boer and Hahne, 1990). The use of contaminated water in washing or handling at the point of sale should also be considered as a risk factor for cross-contamination (Chai et al., 2007).

Campylobacter spp. strains were isolated from lettuce samples purchased in street markets $(3 / 20 ; 15 \%)$, where handling of these vegetables is more frequent. In order to keep their appearance fresh, vegetables are constantly sprinkled with water that is stored in containers and kept behind the stalls, which is an unhygienic procedure. Although vegetables sold in street markets appear to be freshly harvested because they are regularly sprayed, this procedure preserves the viability of Campylobacter spp.

$C d t$ genes were detected in $83.3 \%(20 / 24)$ of the $C$. jejuni strains isolated from broiler carcasses and lettuce heads. In the present study, the percentage of $C$. jejuni strains that carried the $c d t$ complex was similar to that reported in the international literature. In Poland, Rozynek et al. (2005) detected the three $c d t$ genes in $100 \%$ of the $C$. jejuni strains found in poultry carcasses from supermarkets and slaughterhouses. Samosornsuk et al. (2007), in Thailand, detected the $c d t$ genes in $95 \%$ of the $C$. jejuni strains isolated from poultry. Talukder et al. (2008) identified $C$. jejuni in patients with diarrhea in Bangladesh, and identified the genes $c d t A, c d t B$ and $c d t C$ in $97.5 \%$ of the strains. According to these authors, CDT production is associated with the strains that cause enteritis in humans.

The presence and expression of the three genes are necessary for functional activity of the CDT toxin (Jeon et al., 2005). Therefore, $80 \%(16 / 20)$ of the 20 strains that carried the $c d t$ genes were potentially virulent, once they had $c d t A, c d t B$ and $c d t C$, simultaneously. In $20 \%(4 / 20)$ of the strains, only one $c d t$ gene was detected $(c d t B$ or $c d t C)$.

According to Martinez et al. (2006), all C. jejuni strains have $c d t$ genes, and most of them show toxin activity. However, there are exceptions of rare isolates that mutate and do not show activity of these genes. These authors also sequenced and characterized CDT-negative genes, and observed the presence of $c d t A, c d t B$ and $c d t C$ pseudo-genes with deletions in their sequences. Asakura et al. (2007) also observed that some $c d t$ genes may not be identified because of mutations, such as nucleotide deletion, insertion or substitution, and suggest that these mutations may affect toxin activity.

As for C. coli strains isolated from broiler carcasses and lettuce, $100 \%(3 / 3)$ were positive for the three $c d t$ genes simultaneously. In the present study, the percentage of $C$. coli strains that carried the $c d t$ complex was similar to that reported by other authors in different countries. In Portugal, Fernandes et al. (2010) detected $c d t A$ and $c d t C$ in $99.4 \%$ and $c d t B$ in $98.8 \%$ of the strains isolated from food samples. In Italy, Ripabelli et al. (2010) detected the $c d t$ gene complex in $94.4 \%$ of the C. coli strains isolated from foods, animals and humans.

There are no reports in Brazil and other countries on the study of $c d t$ genes in Campylobacter spp. strains isolated from vegetables, making this group of foods a new source of contamination with $C$. jejuni and $C$. coli strains potentially virulent for humans and animals, with possible public health risk.

This is the first time that the $c d t$ gene cluster was detected in C. coli strains from broiler carcasses, and C. jejuni and $C$. coli strains in samples of lettuce, in the state of São Paulo, Brazil. These results may provide yet unpublished data on the occurrence of Campylobacter spp. strains that carry the genes for CDT from foods of animal, and mainly vegetable origin. They also show that potentially virulent strains remain viable in broiler carcasses and in lettuce samples in the points of sale. Therefore, the contamination of foodstuffs by these microorganisms should not be ignored. Preparation should be carried out in optimal conditions of hygiene, especially for ready-to-eat products, or whenever there is a possibility of cross-contamination during handling.

\section{Acknowledgments}

Grant\#2007/52441-0, São Paulo Research Foundation (FAPESP).

\section{References}

Abadias M, Usall J, Anguera M, Solsona C, Viñas I (2008) Microbiological quality of fresh, minimally-processed fruit and vegetables, and sprouts from retail establishments. Int J Food Microbiol 123:121-129.

Abuoun M, Manning G, Cawthraw SA, Ridley A, Ahmed IH, Wassenaar TM, Newell DG (2005) Cytolethal Distending Toxin (CDT)-Negative Campylobacter jejuni strains and anti-CDT neutralizing antibodies are induced during human infection but not during colonization in chickens. Infect Immun 73:3053-3062.

Altekruse SF (1998) Campylobacter jejuni in foods. J Am Vet Med Assoc 213:1734-1735.

Asakura M, Samosornsuk W, Taguchi M, Kobayashi K, Misawa N, Kusumoto M, Nishimura K, Matsuhisa A, Yamasaki S (2007) Comparative analysis of citolethal distending toxin $(c d t)$ genes among Campylobacter jejuni, C. coli and C. fetus strains. Microbial Pathogenesis 42:174-183. 
Asakura M, Samosornuk W, Hinenoya A, Misawa N, Nishimura K, Matsuhisa A, Yamasaki S (2008) Development of a cytolethal distending toxin $(c d t)$ gene-based species-specific multiplex PCR assay for the detection and identification of Campylobacter jejuni, Campylobacter coli and Campylobacter fetus. FEMS Immun Med Microbiol 52:260-266.

Brandl MT, Haxo AF, Bates AH, Mandrell RE (2004) Comparison of survival of Campylobacter jejuni in the phylosphere with that in the rhizosphere of spinach and radish plants. Appl Environ Microbiol 70:1182-1189.

Butzler JP, Oosterman J (1991) Campylobacter: pathogenicity and significance in foods. Int J Food Microbiol 12:1-8.

Callegari-Jacques SM (2003) Bioestatística: Princípios e Aplicações. Artmed, Porto Alegre. 256p.

Carvalho AC, Ruiz-Palacios GM, Ramos-Cervantes P, Cervantes L, Jing X, Picckering LK (2001) Molecular characterization of invasive and noninvasive Campylobacter jejuni and Campylobacter coli isolates. J Clin Microbiol 39:13531359.

Carvalho AF, Silva DM, Azevedo SS, Piatti RM, Genovez ME, Scarcelli E (2010) Detecção dos genes da toxina citoletal distensiva em estirpes de Campylobacter jejuni isoladas de carcaças de frangos. Arq Bras Med Vet Zootec 62:10541061.

Castro AGM, Genovez ME, Scarcelli E, Torres AP, Cardoso MV, Paschoal AP, Souza CAI, Carrasco S (1997) Monitoramento de Campylobactrer spp. ao longo da linha de abate de frangos de corte. Arq Inst Biol 64:21-26.

Chai LC, Robin T, Ragavan UM, Gunsalam JW, Bakar FA, Ghazali FM, Radu S, Kumar MP (2007) Thermophilic Campylobacter spp. in salad vegetables in Malaysia. Int $\mathrm{J}$ Food Microbiol 117:106-111.

Cortez ALL, Carvalho ACFB, Scarcelli E, Miyashiro S, Vidal Martins AMC, Bürger KP (2006) Survey of chicken abattoir for the presence of Campylobacter jejuni and Campylobacter coli. Rev Inst Med Trop São Paulo 48:307310.

De-Boer E, Hahne M (1990) Cross-contamination with Campylobacter jejuni and Salmonella spp. from raw chicken products during food preparation. J Food Prot 53:1063-1068

Dean AG (1994) EpiInfo version 6: a word-processing, database, and statistic program for public health on IBM-compatible microcomputers. Atlanta: Center for Diseases Control and Prevention. 601 p.

Evans MR, Ribeiro CD, Salmon RL (2003) Hazards of healthy living: bottled water and salad vegetables as risk factors for Campylobacter infection. Emerg Infect Diseas 9:12191225.

Eyigor A, Dawason KA, Langlois BE, Pickett CL (1999) Detection of cytolethal distending toxin activity and $c d t$ genes in Campylobacter spp. isolates from chicken carcasses. Appl Environ Microbiol 65:1501-1505.

Fernandes M, Mena C, Silva J, Teixeira P (2010) Study of Cytolethal Distending Toxin ( $c d t)$ in Campylobacter coli using a Multiplex Polymerase Chain Reaction assay its distribuition among clinical and food strains. Foodborne Pathog Dis 7:103-106.
Hunt JM, Abeyta C, Tran T (2001) Campylobacter. In: FDAs Bacteriological Analytical Manual Online, 8 ed. Revision A. chap. 7. http://www.cfsan.fda.gov/ ebam/bam-7.html.

Hussain I, Shahid Mahmood M, Akhtar M, Khan A (2007) Prevalence of Campylobacter species in meat, milk and other food commodities in Pakistan. Food Microbiol 24:219-222.

Jeon B, Itoh K, Ryu S (2005) Promoter analysis of Citolethal Distending Toxin genes ( $c d t A, B$ and $C$ ) and effect of a luxS mutation on CDT production in Campylobacter jejuni. Microbiol Immunol 49:599-603.

Kang YS, Cho YS, Yoon SK, Yu MA, Kim CM, Lee JO, Pyun YR (2006) Prevalence and antimicrobial resistance of Campylobacter jejuni and Campylobacter coli isolated from raw chicken meat and human stools in Korea. J Food Protect 69:2915-2923.

Kumar A, Agarwal RK, Bhilegaonkar KN, Shome BR, Bachhil VN (2001) Occurrence of Campylobacter jejuni in vegetables. Int J Food Microbiol 67:153-155.

Linton D, Lawson A J, Owen RJ, Stanley J (1997) PCR detection, identification to species level, and fingerprinting of Campylobacter jejuni and Campylobacter coli direct from diarrheic samples. J Clin Microbiol 35:2568-2572.

Martinez I, Mateo E, Churruca E, Girbau C, Alonso R, Fernandez-Astorga A (2006) Detection of $c d t A, c d t B$, and $c d t C$ genes in Campylobacter jejuni by multiplex PCR. Int J Med Microbiol 296:45-48.

Mead CG, Hudson WR, Hinton MH (1995) Effects of changes in processing to improve hygiene control on contamination of poultry carcasses with Campylobacter. Epidemiol Infect 115:495-500.

Mena C, Rodrigues D, Silva J, Gibbs P, Teixeira P (2008) Occurrence, Identification and Characterization of Campylobacter Species Isolated from Portuguese Poultry Samples Collected from Retail Establishments. Poult Sci 87:187-190.

Park CE, Sanders GW (1992) Occurrence of thermotolerant campylobacters in fresh vegetables sold at farmers' outdoor markets and supermarkets. Canad J Microbiol 38:313-316.

Park SF (2002) The physiology of Campylobacter species and its relevance to their role as foodborne pathogens. Int J Food Microbiol 74:177-188.

Peyrat MB, Soumet C, Maris P, Sanders P (2008) Recovery of Campylobacter jejuni from surfaces of poultry slaughterhouses after cleaning and disinfection procedures: Analysis of a potential source of carcass contamination. Int $\mathrm{J}$ Food Microbiol 124:188-194.

Prencipe V, Parisciani G, Calistri P, Caporale CM, Iannitto G, Morelli D, Pomilio F, Prochowski D, Migliorati G (2007) Thermotoletant Campylobacter in poultry meat marketed in the Abruzzo and Molise regions of Italy: prevalence and contaminations levels. Vet Ital 43:157-165.

Ripabelli G, Tamburro M, Minelli F, Leone A, Sammarco L (2010) Prevalence of virulence-associated genes and cytolethal distending toxin production in Campylobacter spp. isolated in Italy. Comp Imumun Microbiol Infect Dis 33:355364.

Rozynek E, Dzierzanowska-Frangat K, Jozwiak P, Popowski J, Korsak D, Dzierzanowska D (2005) Prevalence of potential virulence markers in Polish Campylobacter jejuni and Campylobacter coli isolates obtained from hospitalized children and from chicken carcasses. J Med Microbiol 54:615619. 
Sakuma H, Franco DGM, Fernadez H (1992) Occurrence of Campylobacter jejuni an Campylobacter coli in retail raw chicken meat and giblets in São Paulo, Brazil. Rev Microbiol 23:13-16.

Samosornsuk W, Asakura M, Yoshida E, Taguchi T, Nishimura K, Eampokalap B, Phongsisay V, Chaicumpa W, Yamasaki S (2007) Evaluation of a Cytolethal Distending Toxin $(c d t)$ gene-based sapecies-specific Multiplex-PCR assay for the identification of Campylobacter strains isolated from poultry in Thailand. Microbiol Immunol 51:909-917.

Scarcelli E, Piatti RM, Harakava R, Miyashiro S, Campos Fernandes FM, Campos FR, Francisco W, Genovez ME, Richtzenhain LJ (2005) Molecular subtyping of Campylobacter jejuni subsp. jejuni strains isolated from different animal species in the state of Sao Paulo, Brazil. Braz J Microbiol 36:378-382

Smith JL, Bayles DO (2006) The contribution of cytolethal distending toxin to bacterial pathogenesis. Crit Rev Microbiol, 32:227-248

Talukder K A, Aslam M, Islam Z, Azmi IJ, Dutta DK, Hossain S, Nur-E-Kamal A, Nair GB, Cravioto A, Sack DA, Endtz HP (2008) Prevalence of virulence genes and cytolethal distending toxin production in Campylobacter jejuni isolates from diarrheal patients in Bangladesh. J Clin Microbiol 46:14851488.

Wassenaar TM (1997) Toxin production by Campylobacter spp. Clin Microbiol Rev 10:466-476.

All the content of the journal, except where otherwise noted, is licensed under a Creative Commons License CC BY-NC. 